\title{
Geometry of Neonatal and Adult Red Blood Cells
}

\author{
OTWIN LINDERKAMP, ${ }^{(24)}$ PAUL Y. K. WU, AND HERBERT J. MEISELMAN ${ }^{(26)}$ \\ Department of Physiology and Biophysics and Department of Pediatrics, University of Southern California, School of \\ Medicine, Los Angeles, CA, USA
}

\begin{abstract}
Summary
Red blood cell (RBC) geometry is a determinant of $\mathrm{RBC}$ deformability, survival time, osmotic resistance, and oxygen uptake. Because accurate information on the geometry of neonatal RBC appears lacking, a micropipette technique was employed to measure surface area and volume of individual neonatal and adult $\mathrm{RBC}$. In addition, $\mathrm{RBC}$ diameter was determined microscopically. From these measurements, surface area index (actual surface area divided by area of sphere of same volume), swelling index (maximal volume divided by actual volume), minimum cylindrical diameter and mean thickness of RBC were calculated. Compared to adult cells, the volume of neonatal $\mathrm{RBC}$ was $21 \%$ larger, their surface area was $13 \%$ greater and their diameter $11 \%$ wider. The surface area-to-volume ratio of the neonatal $R B C$ was $1.42 \pm 0.08$ and that of the adult $\mathrm{RBC}$ was $1.49 \pm 0.06(P<0.05)$. The minimum cylindrical diameter of the neonatal $R B C$ was $3.04 \pm 0.25 \mu \mathrm{m}$ and that of the adult $\mathrm{RBC}$ was $2.81 \pm 0.23 \mu \mathrm{m}(P<0.05)$. Mean $\mathrm{RBC}$ thickness, surface area index and swelling index were not significantly different.
\end{abstract}

\section{Abbreviation}

RBC, red blood cell

Accurate knowledge about the geometry of red blood cells (RBC) is important for the study of deformability, survival time, osmotic resistance, and oxygen uptake of RBC (5). The geometry of $\mathrm{RBC}$ is defined by measureable dimensions as the cellular volume, membrane surface area, cell diameter and thickness, and by indices calculated from measured values. These calculated indices include the surface area index (actual surface area divided by area of a sphere of same volume) and the swelling index (maximal volume which a RBC can achieve by swelling divided by actual volume).

The surface area index is a measure of the excess surface area beyond that required to enclose the cellular volume. A surface area index of 1.39 [the normal value for adult $\mathrm{RBC}(13)$ ] indicates an excess surface area of $39 \%$. RBC need excess membrane surface area to deform and to adopt various shapes during their passage through the microcirculation. A membrane-bound sphere possesses the minimal surface area required to enclose its volume and therefore is relatively rigid because deformation can only occur via increased membrane surface area.

The swelling index is a measure of the swelling capacity of $\mathrm{RBC}$. A swelling index of 1.62 [the normal value for adult $\mathrm{RBC}$ (13)] indicates that the volume of a RBC can increase by $62 \%$ before it reaches spherical shape and then hemolyzes. The swelling index is related to the osmotic resistance which is an indirect measure of the swelling ability of RBC.

Another calculated RBC geometric property is the minimum cylindrical diameter which a cell can assume in a small cylindrical channel. This parameter indicates the minimal diameter of a capillary through which a $\mathrm{RBC}$ can pass without a change in its volume. The minimum cylindrical diameter is an important de- terminant of the flow behavior of $\mathrm{RBC}$ in the microcirculation. The minimum cylindrical diameter is also a major determinant of the flow rate through micropore filters and the pressure required to aspirate $\mathrm{RBC}$ into small micropipettes (5).

The volume of RBC in full-term newborn infants is about $20 \%$ higher than in adults and the diameter of neonatal RBC is increased by about $10 \%$ compared to adults $(16,18)$. Riegel et al. (18) computed the surface area of neonatal $\mathrm{RBC}$ from measured diameters of dried erythrocytes and calculated mean cell thickness using a disc model. This assumption of a disc model, however, results in an overestimation of the surface area (5). Direct measurements of the surface area and thus calculated values of the surface area index, the swelling index, and the minimum cylindrical diameter do not appear to exist for neonatal RBC.

The present study was designed to measure geometric properties of neonatal and adult RBC using micropipette techniques. Volume, surface area, and diameter of neonatal RBC were found to be higher than adult cells. Mean thickness, surface area index, and swelling index were similar in both groups, whereas the surface area-to-volume ratio of neonatal $\mathrm{RBC}$ was significantly decreased and the minimum cylindrical diameter was increased when compared to adult cells. This might contribute to decreased filterability $(1,7,22)$, increased aspiration pressure (15), and shortened life span (6) of neonatal RBC.

\section{MATERIALS AND METHODS}

Placental blood samples from 10 healthy newborn infants with gestational ages of 39-41 wk and birth weights of 3280-3590 g were studied with approval of the University of Southern California Human Subjects Research Committee. Immediately after cord-clamping, $10 \mathrm{ml}$ of blood were collected from the placenta into heparin $(5 \mathrm{IU} / \mathrm{ml})$. Adult blood samples were collected from 10 healthy laboratory personnel via venipuncture into heparin. All measurements were made at room temperature $\left(22 \pm 1^{\circ} \mathrm{C}\right)$ within $4 \mathrm{~h}$ after collection. Red blood cells (RBC) were isolated by centrifugation at $2000 \times \mathrm{g}$ for $10 \mathrm{~min}$, and the plasma and buffy coat were removed by gentle aspiration. The cells were washed twice via centrifugation-aspiration in phosphate buffered saline (PBS, $0.030 \mathrm{M} \mathrm{KH}_{2} \mathrm{PO}_{4}+\mathrm{Na}_{2} \mathrm{HPO}_{4}$ plus $1 \mathrm{~g} /$ liter human serum albumin; pH $7.40 \pm 0.02$ at $25^{\circ} \mathrm{C} ; 297$ mosmole $/ \mathrm{kg}$ ). After the second wash, the cells were suspended at a low packed cell volume $(0.1 \%)$ in the PBS, then tested to evaluate their geometric properties. All solutions were filtered through $0.45 \mu \mathrm{m}$ Millipore filters immediately before use. The removed plasma was centrifuged a second time at $20,000 \times g$ for $15 \mathrm{~min}$ to remove platelets.

The measurements of the geometric properties of RBC were performed using micropipettes $(13,17)$. Experimental details of the micropipette technique have been given elsewhere (13). One neonatal and one adult blood sample were studied on the same day using the same micropipette; $40 \mathrm{RBC}$ were tested from each donor. Micropipettes with an internal diameter of the tip of 1.9$2.1 \mu \mathrm{m}$ were filled with plasma of the donor, then flushed with the albuminated PBS used to suspend the cells. This procedure prevents $R B C$ adhesion to the glass walls of the pipette (3). After the 
pressure in the pipette was brought to zero, a $\mathrm{RBC}$ was aspirated by adjusting the pressure to $-15 \mathrm{mmH}_{2} \mathrm{O}$. One portion of the cell entered the pipette assuming a cylindrical shape, whereas the outer portion became spherical (Fig. la). The cellular surface area (A) and volume (V) were calculated from the diameter of the pipette $\left(D_{p}\right)$, the length of the cell projection in the pipette (L) and the diameter of the outer portion $\left(D_{s}\right)$ :

$$
\begin{aligned}
& \mathrm{A}=\pi\left(\mathrm{LD}_{\mathrm{p}}+\mathrm{D}_{\mathrm{s}}{ }^{2}-\frac{\mathrm{D}_{\mathrm{p}}{ }^{2}}{4}\right) \\
& \mathrm{V}=(\pi / 24)\left(6 \mathrm{LD}_{\mathrm{p}}{ }^{2}+4 \mathrm{D}_{\mathrm{s}}{ }^{3}-\mathrm{D}_{\mathrm{p}}{ }^{3}\right)
\end{aligned}
$$

These formulas do not consider the segment of the outer sphere, which is "cut off" by the tip of the pipette. This results in an error of less than $1 \%$ for surface area and volume. The diameter (D) of each RBC was measured before the cells were aspirated.

From the measured RBC parameters (surface area, A, volume, $\mathrm{V}$, diameter, $\mathrm{D}$ ), mean thickness, minimum cylindrical diameter, surface area index, and swelling index (Fig. 1) were calculated (2, 13) as described below. Mean RBC thickness was calculated using a disc model, i.e., as the ratio of the volume and area of a circle:

$$
\text { Mean thickness }=\frac{4 \mathrm{~V}}{\left(\pi \mathrm{D}^{2}\right)}
$$

The minimum cylindrical diameter $\left(D_{c}\right)$ was calculated from the area and volume of $\mathrm{RBC}$ using equations for a cylinder with spherical end caps (Fig. 1b):

$$
\begin{aligned}
& \mathrm{A}=\pi \mathrm{D}_{\mathrm{c}}{ }^{2}+\mathrm{D}_{\mathrm{c}} \mathrm{L} \\
& \mathrm{V}=\frac{\pi \mathrm{D}_{\mathrm{c}}{ }^{3}}{6}+\frac{\mathrm{D}_{\mathrm{c}}{ }^{2} \mathrm{~L}}{4}
\end{aligned}
$$

eliminating $L$ yields

$$
\mathrm{V}=\frac{\mathrm{AD}_{\mathrm{c}}}{4}-\frac{\pi \mathrm{D}_{\mathrm{c}}^{3}}{12}
$$

Both the surface area index and the swelling index were calculated from the equations for the volume $\left(V_{s}\right)$ and surface area $\left(A_{s}\right)$ of a sphere:

$$
\mathrm{V}_{\mathrm{s}}=\frac{4 \pi \mathrm{r}^{3}}{3} \text { and } \mathrm{A}_{\mathrm{s}}=4 \pi \mathrm{r}^{2}
$$

eliminating $\mathrm{r}$ yields

$$
\mathrm{V}_{\mathrm{s}}=0.094 \mathrm{~A}_{\mathrm{s}}{ }^{1.5} \text { or } \mathrm{A}_{\mathrm{s}}=4.84 \mathrm{~V}_{\mathrm{s}}^{2 / 3}
$$

The surface area index is the ratio of the actual RBC surface area (A) to the area of a sphere $\left(\mathrm{A}_{\mathrm{s}}\right)$ of the same volume (Fig. 1d):

$$
\text { Surface area index }=\frac{\mathrm{A}}{\mathrm{A}_{\mathrm{s}}}=\frac{\mathrm{A}}{4.84 \mathrm{~V}_{\mathrm{s}}^{2 / 3}}
$$

The swelling index is the maximal (spherical) volume which a $\mathrm{RBC}$ can achieve by swelling $\left(\mathrm{V}_{\mathrm{s}}\right)$ divided by its actual volume (V):

$$
\text { Swelling index }=\frac{V_{s}}{V}=\frac{0.094 A^{1.5}}{V}
$$

Note that the surface area index, which is the reciprocal of the sphericity index (2), has a limiting value of 1.0 for a sphere. The swelling index also has a limiting value of 1.0 for a spherical shape.

Mean cellular volume (MCV) and sample standard deviation in isotonic, filtered PBS were measured electronically with a computerized Electrozone-Celloscope (Particle Data Inc., Model $112 \mathrm{LA} / \mathrm{ADCW}$ ) equipped with a $76 \mu \mathrm{m}$ orifice and operating with a $20 \%$ rejection level to eliminate the artifact caused by nonaxial transit of the RBC. (a)

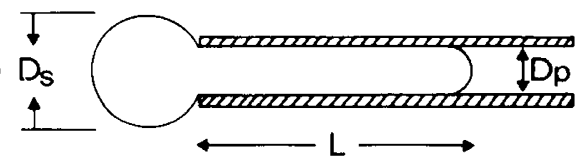

(b)

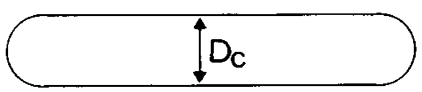

(c)

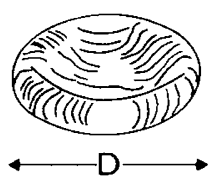

(d)
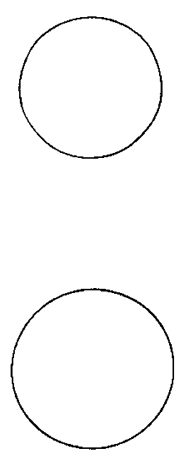

Fig. I. Schematic illustration of the geometrical properties of an average adult red blood cell (RBC) (volume, V, 88.4 fl; surface area, A, 134.3 $\mu \mathrm{m}^{2}$; diameter of resting cell, $\mathrm{D}, 7.79 \mu \mathrm{m}$; see Table 1). (a) determination of $\mathrm{RBC}$ volume and surface area (pipette diameter, $\mathrm{D}_{\mathrm{p}}, 2.0 \mu \mathrm{m}$; diameter of sphere, $D_{s}, 4.7 \mu \mathrm{m}$; length of cell projection in the pipette, $\mathrm{L}, 10.8 \mu \mathrm{m}$ ); (b) minimum cylindrical diameter $\left(\mathrm{D}_{\mathrm{c}}, 2.8 \mu \mathrm{m}\right)$; (c) resting $\mathrm{RBC}$ (diameter, $\mathrm{D}, 7.79 \mu \mathrm{m})$; (d) sphere with volume of RBC (V, $88.4 \mathrm{fl})$ and calculated minimum (spherical) area $\left(A_{s}, 96.6 \mu \mathrm{m}^{2}\right)$; surface area index is the ratio of actual RBC surface area to the calculated surface area of this sphere $(134.3 / 96.6=1.39)$; and (e) sphere with surface area of RBC (A, 134.3 $\left.\mu \mathrm{m}^{2}\right)$ and calculated maximal (spherical) volume $\left(\mathrm{V}_{\mathrm{s}}, 146.3 \mathrm{fl}\right)$; swelling index is the ratio of the calculated spherical volume to the actual RBC volume $(146.3 / 88.4=1.66)$

Statistical analyses were performed to test for differences between neonatal and adult RBC using a two-tailed unpaired $t$ test with 18 degrees of freedom. Two standard deviations were used: (1) the standard deviations of the single measurements done in each group (e.g., 400 measurements) and (2) the standard deviations of the 10 sample means in each of the two groups. The first standard deviation reflects the spread of the individual RBC in all 10 samples and is therefore larger than the second standard deviation which reflects only the spread of the sample means (Table 1). Nevertheless, we used 18 degrees of freedom for both tests because the number of degrees of freedom should be based on the number of samples rather than on the total number of observations because of possible interindividual differences (21). Mean values and standard deviations were also calculated for the RBC parameters of each donor and showed no significant differences among the 10 donors in each group using analysis of variance and Bartlett test (21).

\section{RESULTS}

The measured and calculated geometric properties of neonatal and adult $R B C$ are shown in Table 1 . RBC volumes measured by the electronic orifice system (MCV) and by the micropipette 
Table 1. Geometric properties of neonatal and adult red blood cells $(R B C)^{1}$

\begin{tabular}{lcc}
\hline & Adult RBC & Neonatal RBC \\
\hline $\begin{array}{l}\text { Mean cellular volume } \\
(\text { fl) (celloscope) }\end{array}$ & $87.2 \pm 14.0(3.2)$ & $105.9 \pm 22.3^{2}\left(4.7^{3}\right)$ \\
$\begin{array}{l}\text { Volume (fl) (micropi- } \\
\text { pette) }\end{array}$ & $88.4 \pm 12.8(3.8)$ & $106.8 \pm 22.7^{2}\left(5.4^{3}\right)$ \\
Surface area $\left(\mu \mathrm{m}^{2}\right)$ & $134.3 \pm 13.5(6.1)$ & $151.6 \pm 22.2^{2}\left(7.2^{3}\right)$ \\
Diameter $(\mu \mathrm{m})$ & $7.79 \pm 0.64(0.34)$ & $8.62 \pm 0.73\left(0.38^{3}\right)$ \\
Mean thickness $(\mu \mathrm{m})$ & $1.86 \pm 0.28(0.10)$ & $1.83 \pm 0.31(0.12)$ \\
Surface area/volume & $1.49 \pm 0.06(0.03)$ & $1.42 \pm 0.08^{2}\left(0.03^{3}\right)$ \\
Surface area index & $1.39 \pm 0.08(0.03)$ & $1.39 \pm 0.09(0.04)$ \\
Swelling index & $1.66 \pm 0.09(0.03)$ & $1.64 \pm 0.10(0.05)$ \\
Minimum cylindrical & $2.81 \pm 0.23(0.12)$ & $3.04 \pm 0.25^{2}\left(0.13^{3}\right)$ \\
$\quad$ diameter $(\mu \mathrm{m})$ & &
\end{tabular}

'Values represent mean \pm 1 S.D. Note that the first S.D. reflects the spread of the 400 red blood cells studied in each group ( $40 \mathrm{RBC}$ from each of the 10 donors), whereas the values in parentheses reflect the spread of the 10 sample means.

${ }^{2} P<0.05$ when compared to adult red cells (two-tailed unpaired $t$ test, 18 degrees of freedom).

${ }^{3} P<0.001$ when compared to adult red cells (two-tailed unpaired $t$ test, 18 degrees of freedom).

technique did not show meaningful differences. Compared to adult cells, the volume of neonatal cells was $21 \%$ larger, their surface area was $13 \%$ greater and their diameter $11 \%$ wider. The surface area-to-volume ratio of the neonatal $\mathrm{RBC}$ was significantly decreased and their minimum cylindrical diameter was increased when compared to adult cells. There were no significant differences between the neonatal and adult RBC for the following parameters: (1) mean RBC thickness calculated from cell diameter and volume data; (2) surface area index calculated as ratio of actual surface area and area of a sphere of same volume; and (3) swelling index calculated as ratio of maximal volume and actual volume.

\section{DISCUSSION}

The micropipette technique for determination of surface area and volume of individual $\mathrm{RBC}$ yields reproducible and reliable results when pipettes with an internal diameter of about $2 \mu \mathrm{m}$ are used with aspiration pressures of $15 \mathrm{~mm} \mathrm{H}_{2} \mathrm{O}(13,17)$. Diffraction effects within the optical system limit the accuracy of linear measurements to about $0.25-0.50 \mu \mathrm{m}$. In addition, optical distortion caused by the glass micropipette makes an exact determination of the pipette inside diameter somewhat difficult (4). These possible absolute measurement errors appear to be of relatively minor importance in this study, inasmuch as the same pipette was used for one neonatal and one adult RBC sample and because the micropipette measurements of RBC volumes (V) are in good agreement with volumes independently determined via the electronic orifice-type system (MCV, see Table 1).

The micropipette measurements of adult RBC surface area and volume agree with other reports on adult cells $(2,4,5,13,17)$. The volume and diameter measurements of neonatal cells also are in agreement with other studies $(16,18)$. Note that calculation of surface area from measured diameter and mean thickness by assuming a disc shape for the RBC overestimates the surface area: the calculated surface areas are $166 \mu \mathrm{m}^{2}$ for neonatal $\mathrm{RBC}$ and $141 \mu \mathrm{m}^{2}$ for adult cells. These figures are similar to those calculated by Riegel et al. (18), but are $9.5 \%$ greater (neonatal) or $5.0 \%$ greater (adult) than our directly measured values (Table 1).

Volume, surface area, and diameter were all larger for neonatal cells than for adult RBC (Table 1). The surface area-to-volume ratio of the neonatal RBC was significantly decreased; however, larger cells need lower surface area-to-volume ratios than smaller $\mathrm{RBC}$ to maintain the same excess surface area. RBC need excess surface area to deform and to adopt various shapes. Deformation enables RBC to adapt to high shear forces in large vessels with rapid flow and to pass through narrow capillaries and splenic slits with diameters less than that of the resting RBC. The similar surface area index (i.e., excess surface area) of the neonatal and adult $\mathrm{RBC}$ indicates that they have the same shape and the same deformability provided that other factors affecting RBC deformability are not different $(15,16)$. This agrees with findings of similar deformability for neonatal and adult RBC in the rheoscope (16) and in viscometers (14), because cell deformability measured in these devices largely depends on the excess surface area (19).

In narrow cylindrical channels, $\mathrm{RBC}$ have to assume cylindrical shape; therefore, the minimum cylindrical diameter (i.e., the smallest cylinder a $\mathrm{RBC}$ can enter without loss of volume) is an important determinant for the behavior of $\mathrm{RBC}$ in small micropipettes and in filter pores $(2,3,5)$. The larger minimum cylindrical diameter of neonatal RBC might explain why the pressure required to aspirate neonatal $\mathrm{RBC}$ into micropipettes with an internal diameter of $3.3 \mu \mathrm{m}$ is increased (15) and why the filtration rate of neonatal $\mathrm{RBC}$ through micropore filters is decreased compared to adults $(1,7,22)$.

The minimum cylindrical diameter of the neonatal $\mathrm{RBC}$ was about $8 \%$ higher than that of the adult cells $(3.04 \pm 0.25$ versus $2.81 \pm 0.23 \mu \mathrm{m}$, Table 1). This difference appears small but it may be crucial in capillaries and in splenic pores with diameters of about $3 \mu \mathrm{m}$. The increased minimum cylindrical diameter of neonatal $\mathrm{RBC}$ might also contribute to their shortened life span when compared to adult RBC (6) because in the spleen, $\mathrm{RBC}$ are transitorily trapped and concentrated (12). The increased minimum cylindrical diameter might decrease the rate of passage through the small splenic slits thereby aiding in destruction of RBC by macrophates (11).

The calculated swelling indices indicate that both neonatal and adult RBC in isotonic solution can swell by about $65 \%$ until they reach spherical shape and hemolyze. This agrees with the finding of similar osmotic resistance of neonatal (placental) and adult RBC (20).

The mean thickness of $\mathrm{RBC}$ is of importance for the dynamics of oxygen uptake by the cell (9). The similar mean thickness of neonatal and adult $\mathrm{RBC}$ corresponds to the finding of equal rates of oxygen uptake for neonatal and adult $\mathrm{RBC}(8)$. This also indicates that the decreased surface area-to-volume ratio of neonatal RBC does not impair oxygen uptake, which contradicts the calculations of Jones (10). In narrow capillaries with diameters of about $3 \mu \mathrm{m}$, where RBC have to assume cylindrical shapes, the oxygen exchange between RBC and surrounding plasma might be slightly impeded as a result of the increased mean cylindrical diameter.

\section{REFERENCES AND NOTES}

1. Buchan, P. C.: Evaluation and modification of whole blood filtration in the measurement of erythrocyte deformability in pregnancy and the newborn. $\mathrm{Br}$. J. Haematol., 45: 97 (1980)

2. Canham, P. B. and Burton, A. C.: Distribution of size and shape in populations of normal human red cells. Circ. Res., 22: 405 (1968).

3. Cokelet, G. R., Bush, R. W., and La Celle, P. L.: Electroviscous flow and electrophoretic motion during erythrocyte entry in a glass capillary in the presence of applied electric potential gradients. Pflügers Arch., 390: 94 (1981).

4. Evans, E. and Fung, Y. C.: Improved measurements of the erythrocyte geometry. Microvasc. Res., 4: 335 (1972).

5. Fung, Y. C., Tsang, W. C. O., and Patitucci, P.: High-resolution data on the geometry of red blood cells. Biorheology, 18: 369 (1981).

6. Garby, L., Sjölin, S., and Viulle, J. C.: Studies on the erythrokinetics of infancy. V. Estimation of the life span of red cells in the newborn. Acta Paediatr. Scand., 53: 165 (1964).

7. Gross, G. P. and Hathaway, W. E.: Fetal erythrocyte deformability. Pediatr. Res., 6: 593 (1972).

8. Holland, R. A. B.: Kinetics of combination of $\mathrm{O}_{2}$ and $\mathrm{CO}$ with human hemoglobin $F$ in cells and in solution. Respir. Physiol., 3: 307 (1967).

9. Holland, R. A. B. and Forster, R. E.: The effect of size of red cells in the kinetics of their oxygen uptake. J. Gen. Physiol., 49: 727 (1966).

10. Jones, D. A.: The importance of surface area/volume ratio to the rate of oxygen uptake by red cells. J. Gen. Physiol., 74: 643 (1979) 
11. Kay, M. M. B.: Mechanism of removal of senescent cells by human macrophages in situ. Proc. Natl. Acad. Sci., 72: 3521 (1975).

12. Linderkamp, O., Berg, D., Betke, K., Köferl, F., Kriegel, H., and Riegel, K. P.: Blood volume and hematocrit in various organs in newborn piglets. Pediatr. Res., 14: 1324 (1980).

13. Linderkamp, O. and Meiselman, H. J.: Geometric, osmotic and membrane mechanical properties of density-separated human red cells. Blood, 59: 1121 (1982).

14. Linderkamp, O., Meiselman, H. J., Wu, P. Y. K, and Miller, F. C.: Blood and plasma viscosity and optimal hematocrit in the normal newborn infant. Clin. Hemorheol., 1: 575 (1981).

15. Linderkamp, O., Meiselman, H. J., Wu, P. Y. K., and Miller, F. C.: Deformability, geometry and mechanical properties of normal neonatal red blood cells. Pediatr. Res. (Abstract), 16: 208A (1982).

16. Linderkamp, O., Meiselman, H. J., and Wu, P. Y. K.: Deformability of density separated red blood cells in normal newborn infants and adults. Pediatr. Res., 16: 964 (1982)

17. Nash, G. B. and Wyard, S. J.: Changes in surface area and volume measured by micropipette aspiration for erythrocytes ageing in vivo. Biorheology, 17: 479 (1980).

18. Riegel, K., Hilpert, P., and Bartels, H.: Vergleichende Untersuchunger der Erythrocytenmorphologie, des fetalen Hämoglobins aund der Sauerstoffaffin-

Copyright (c) 1983 International Pediatric Research Foundation, Inc. $0031-3998 / 83 / 1704-0250 \$ 02.00 / 0$ ität des Blutes von Säuglingen, Zicklein und Lämmern. Acta Haematol., 25: 164 (1961).

19. Schmid-Schönbein, $H$. and Gaehtgens, P.: What is red cell deformability? Scand J. Clin. Lab. Invest., 41 (Suppl. 156): 13 (1981).

20. Sjölin, S.: The resistance of red cells in vitro. Acta Paediatr. Scand., 43 (Suppl. 98): 1 (1954).

21. Snedecor, G. W. and Cochran, W. G.: Statistical methods. 6th ed. (Iowa State University Press, Ames, 1967).

22. Tillmann, W., Zabel, U., Lakomek, M., and Schröter, W.: Influence of the fluidity of hemoglobin $F$ on the flexibility of red cells of newborn and older infants. Bibl. Anat., 20: 222 (1981).

23. The authors wish to thank Rosalinda Wenby, B.S., for her technical assistance.

24. Dr. Linderkamp is a recipient of a Research Award from the Deutsche Forschungsgemeinschaft (Li 291/2-1). His present address is: Universitäts-Kinderklinik, Lindwurmstr. 4, D-8000 München 2, W-Germany.

25. This research was supported by grants from the National Institutes of Health (HL15722 and HL15162).

26. Requests for reprints should be addressed to: H. J. Meiselman, Sc.D. Department of Physiology and Biophysics, USC School of Medicine, 2025 Zonal Ave., Los Angeles, CA 90033.

27. Received for publication February 5, 1982

28. Accepted for publication June 23, 1982. 